\title{
ADVANCED ANALYSIS AND PERFORMANCE BASED EVALUATION OF CONCRTE FILLED TUBE (CFT) COLUMNS
}

\author{
Jong Wan $\mathrm{Hu}^{1, *}$, Joonam Park ${ }^{2}$, and Roberto T. Leon ${ }^{3}$ \\ ${ }^{1}$ Associate Research Fellow, Office of National R\&D Investment Strategy and Analysis, \\ Korea Institute of S\&T Evaluation and Planning (KISTEP), Seoul, 137-130, South-Korea \\ ${ }^{2}$ Senior Researcher, Korea Railroad Research Institute, Ui-Wang City, Kyung-gi, 437-757, South-Korea \\ ${ }^{3}$ Professor, School of Civil and Environmental Engineering, \\ Georgia Institute of Technology, Atlanta, GA, 30332, USA \\ *(Corresponding author: E-mail: jongp24@kistep.re.kr; fax number: +82-2-589-2191)
}

Received: 5 July 2010; Revised: 6 August 2010; Accepted: 23 August 2010

\begin{abstract}
This paper discusses the design of such composite structures which are based on the advanced methods introduced in the 2005 AISC Specification and the 2005 Seismic Provisions. The 2005 AISC specification explicitly allows the use of the full plastic capacities of concrete-filled tube (CFT) columns for members with slender steel walls and provides substantially larger bending capacities than previous specifications. This study focuses particularly on seismic design following the nonlinear method. The paper begins with an examination of pseudo-elastic design interaction equations and the ductility demand ratios due to combined axial compressive force and bending moment in CFT members. Based on advanced computational simulations for a series of low-rise composite-moment frames, this paper then investigates both building performance and new techniques in an effort to evaluate building damage during a strong earthquake. It is shown that 2 dimensional (2D) equivalent static analyses can provide good design approximations to the force distributions in moment frames subjected to large inelastic lateral loads. Dynamic analyses utilizing strong ground motions generally produce higher strength ratios than those from equivalent static analyses, but on more localized basis. Finally, ductility ratios obtained from nonlinear dynamic analyses are also sufficient to detect which CFT columns undergo significant deformations.
\end{abstract}

Keywords: CFT columns; Interaction ratio; Dynamic loads; Ductility; Composite-moment frames; Frame Analyses

\section{INTRODUCTION}

In the last two decades, concrete-filled steel tubes (CFTs) have received widespread acceptance in many parts of the world, particularly, in Japan and other countries in Southeast Asia. CFTs are used as composite columns in multi-story buildings as well as bridge piers because of their superior ductility and toughness. These outstanding performance characteristics are associated with the synergetic action of its ductile steel and high compressive strength concrete components (e.g. Roder [1]). Some of the advantages of CFT columns over other either steel or reinforced concrete systems include (e.g. Azizinamini and Schneider [2]; Hajjar [3]):

- The use of the stiffening action from concrete to prevent the local buckling of slendersteel wall elements and to permit the efficient utilization of thin steel tubes.

- The use of the confining action by the steel walls to increase both the concrete strength (primarily for circular columns or CCFTs) and its ductility (in both CCFTs and rectangular CTFs, or RCFTs).

- The use of concrete as a heat sink in case of fire so that the CFT element can be erected without any fire-proofing, if minimal reinforcement in the form of bars is incorporated.

- The use of the steel section as the formwork that considerably reduces construction costs and that speeds the completion of the building.

Composite CFT columns are especially suited for moment resisting frames in high seismic areas because they (a) have a high strength to weight ratio due to the confinement effect of concrete core, (b) provide excellent monotonic and dynamic resistance under biaxial bending plus axial force, and 
(c) improve damping behavior (e.g. Hu et al. [4]; Rassati et al. [5]; Green et al. [6]). Composite CFT frames consisting of steel I girder and either rectangular or circular CFT columns can be classified into fully restrained (FR) composite frames when welded connections are used at the panel zones.

Design provisions based on the full plastic behavior of composite members and systems are particularly useful in limit state calculations for both non-seismic and seismic resistant design. The new USA code provisions for composite construction - namely, the American Institute of Steel Construction 2005 Specification for Structural Steel Buildings (e.g. AISC Specification [7]) and the Seismic Provisions for Structural Steel Buildings (e.g. AISC Seismic Provision [8]) - present designers with new guidance on the analysis and design of composite columns and moment resisting frames. The current AISC Specification for composite columns is appropriate for predicting the ultimate capacity of CFT beam-columns determined by means of a simplified full plastic stress distribution. The full plastic interaction diagram for a cross section can be easily generated through exact or piece-wise linear approximations so that any combination of axial load and moment can be easily checked in design. The stress distribution used to evaluate the capacity of composite columns can be considered as a simplified approximation on the ground that the tensile capacities of concrete and, in particular, any tension stiffening effects are ignored. It is also because materials are assumed to behave in a bilinear elasto-plastic manner.

The purpose of this research is two-fold. First, it examines the monotonic and cyclic behavior of CFT beam-columns subjected to both axial and moment loading in an attempt to estimate both the maximum strength and ductility for doubly-symmetric and axisymmetric composite cross sections. Moreover, the ultimate capacities for rectangular/circular CFT beam-columns can be estimated with reasonable accuracy by means of the axial and moment (P-M) interaction formulas provided by 2005 AISC Specification for composite systems. Second, based on the analytical study of CFT cross-sectional strength and ductility, advanced computational simulations are carried out on a series of five story composite-moment resisting frames. The primary aim of this portion of the study is to develop preliminarily performance based damage assessment methods for CFT columns in the low-rise composite-moment frames which are designed in accordance with the 2005 Seismic Provisions when subjected to large seismic loads.

\section{METHODOLOGY}

The case studies in this paper comprise both cross-sectional analyses (composite CFT cross section) on 1D nonlinear beam-column elements with 2D fiber cross sections and nonlinear frame analyses. The numerical experiments are performed using a nonlinear structural analysis program, OpenSEES v.1.7.2 (e.g. Mazzoni et al. [9]). The cross-sectional analyses include both circular and rectangular concrete-filled steel tube (CCFT or RCFT) columns. The cross-sectional specimens were subjected to simulations that first applied a constant axial load and then monotonically increased the bending moments while holding the axial load constant. The simulations utilized fiber models consisting of steel and concrete two-dimensional fiber elements available in the OpenSEES program. The mid-height moment-curvature response $(M-\phi)$ of cross-sectional specimens was extracted in order to estimate the overall rotational capacity of CFT columns. The initial P-M interaction curves were also formulated by cross-sectional analyses. These studies verified that the P-M interaction formulas from 2005 AISC Specification are able to accurately predict the capacity of the CFT beam-columns. These analytical results were used to determine the available curvature ductility ratios for CFT columns (e.g. Varma et al. [10]), and these ratios were employed to assess the performance of composite frames that undergo considerable deformations. 
The assessment methods implemented for composite CFT beam-columns as described above can be extended to the nonlinear frame analyses. Within these frame analyses, both static pushover analyses and nonlinear dynamic time history analyses were performed on $2 \mathrm{D}$ composite-moment resisting frames. Two primary indices were employed to quantify expected performance. The first index, which was used for the static pushover and nonlinear dynamic analysis, will be labeled the elastic strength ratio (ESR) and compares the bending plus axial load ratio generated from the frame analyses to that provided by the section selected in the design process. The second index, which will be only used for the non-linear dynamic analysis, results in the inelastic curvature ductility ratio (ICDR) and compares the required rotational ductility given by the frame analyses with the yield ductility predicted by the cross-section one.

\section{OVERVIEW OF APPLICABLE DESIGN GUIDELINES}

The current 2005 AISC Specification includes design guidelines for composite columns consisting of rolled or built-up structural steel shapes, pipe or hollow steel section (HSS) and structural concrete component acting together as a composite member. To qualify as a concrete filled composite column, the following requirements should be satisfied:

- The cross sectional area of HSS shall be at least 1 percent of the total composite cross section.

- The maximum width-thickness ratio for a rectangular HSS shall be less than or equal to $2.26 \sqrt{E_{s} / F_{y}}$.

- The maximum diameter-thickness ratio for a circular HSS filled with concrete shall be equal to $0.15 E_{s} / F_{y}$.

- Larger slenderness are permitted in the practical design when verified by either experimental tests or advanced analyses.

The 2005 AISC Specification endorses the use of the full plastic stress distribution to calculate cross-sectional strength. The calculations are based on the assumption of linear strain across the section height and perfectly elasto-plastic behavior. The nominal strength is estimated by assuming that the steel has reached its yield stress under either tension or compression and that the concrete has reached its crushing strength under only compression as shown in Figure 1. The corresponding stress on an equivalent concrete stress block is taken as $0.85 f_{c}^{\prime}$ and $0.95 f_{c}^{\prime}$ for RCFT columns and CCFT columns, respectively.

The P-M interaction diagram (see Figure 1) for a composite section, which is based on a full plastic stress distribution, can be generated as a conservative linear interpolation between five points (see Table 1) (e.g. Galambos [11]). Point (A) and Point (B) indicate the plastic axial strength and flexural strength of the section, respectively. Point $(\mathrm{C})$ is anchored to the same flexural capacity as Point (B), but its axial resistance comes from the concrete portion in compression only. Point (D) corresponds to the balanced failure condition, giving the maximum flexural strength for the section and an axial capacity equal to one half of that determined for Point (C). Point (E) is an additional, arbitrarily located point to better capture any bulges in the interaction diagram region corresponding to high axial loads. All five points are defined according to Table 1. For design, a simplified bilinear interpolation may be used between Point (A), ( $\left.\mathrm{D}^{\prime}\right)$ and $(\mathrm{B})$ as also shown in Figure 1. The simplified equations shown in Table 2 can be used for determining an index to use as the member capacity in the computation of the elastic strength ratios (ESRs) of composite beam-columns. This approach is reasonably accurate for steel columns and should provide a conservative estimate for composite structures. 
In so far as the frame designs are concerned, those are governed by the Seismic Provisions (e.g. 2005 AISC Seismic Provision [8]). 4 potential classes of composite moment frame (C-MF) are identified in the Part II of the Seismic Provisions as shown in Table 3. For this study, composite-special moment frames (C-SMF), the most ductile system, were selected for the design of several trial low-rise moment frames. Five-story buildings with long bays (36 ft. or $11 \mathrm{~m}$ ) and perimeter moment resisting systems were used because the intent is to demonstrate the economy of this system for the market segment that constitutes about $90 \%$ of the steel frame construction in the USA. The buildings were designed to the loading prescribed by the ASCE 7-05 (e.g. ASCE [12]). The primary purpose of the ASCE 7-05 standard is to provide information useful to determine the required strength, inter-story drift, and seismic use group for a given structure type and geographical location. The seismic design category (SDC) assigned to a building is a classification based upon the occupancy class and the seismicity of the site. SDC A, B and C generally correspond to structures with the moderate seismic risk or low importance, while SDC D, E, and F require special seismic detailing in the areas of high seismic risk or for critical structures. The designs herein satisfy all the requirements of C-SMF for SDC D in terms of the allowable inter-story drift and the stability limit (e.g. ASCE [12]).

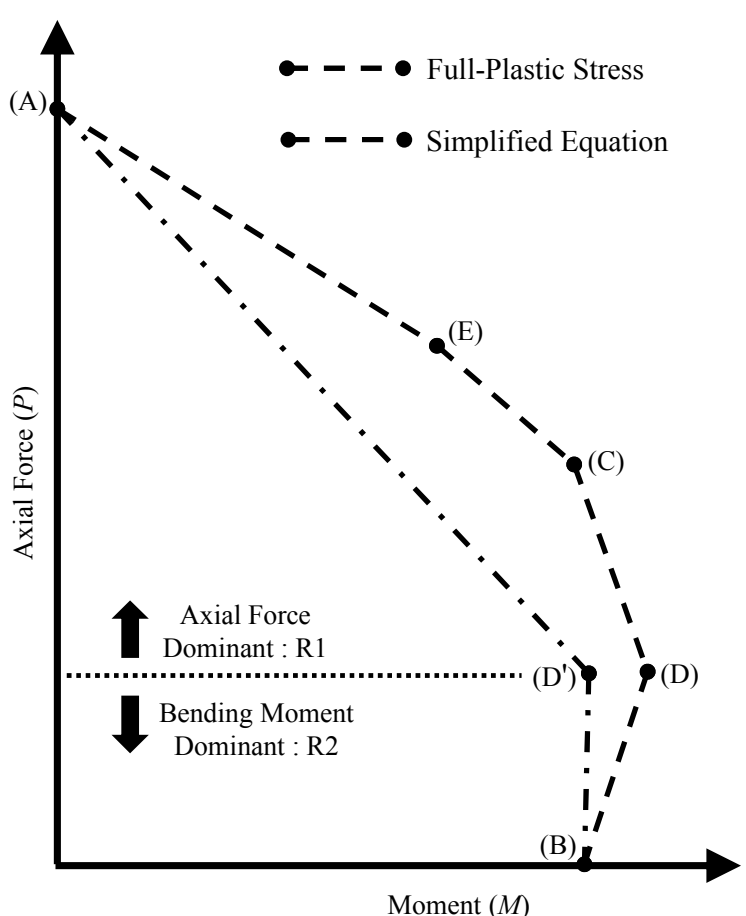

Moment $(M)$
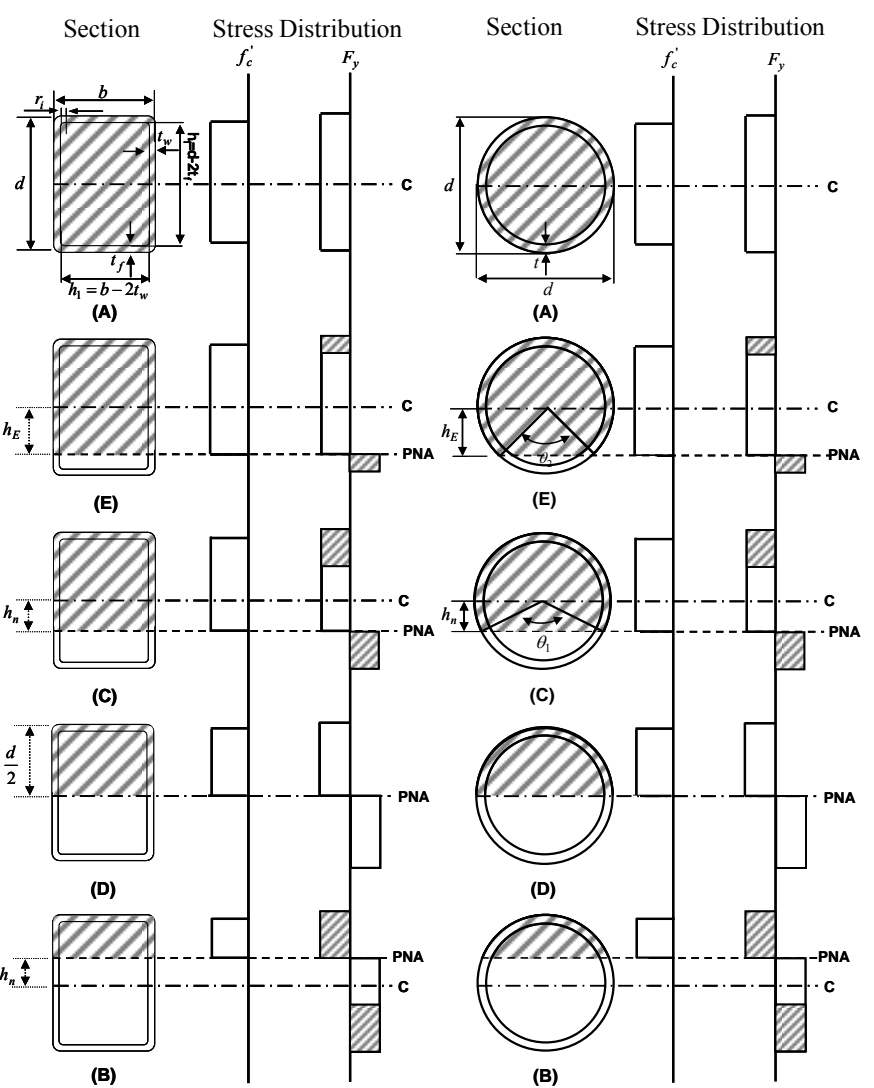

(a) P-M interaction diagrams for composite beam-columns

(b) Full plastic stress distributions for RCFT and CCFT at point A to D

Figure 1. P-M Interaction Diagram for the Composite CFT Section and Full Plastic Stress Distribution Over the Section Height at Five Specific Points 


\section{CFT BEAM-COLUMN ANALYSES}

Two CFT relatively stocky cross sections were modeled as numerical fiber sections using the OpenSEES program as shown in Figure 2. The rectangular tube (HSS16X16X625) has a wall slenderness of 24.5 which is well below the limit of 56.7 allowed by the 2005 AISC specification. Similarly, the circular tube (HSS18X500) has a slenderness of 36 which is also below the limit of 103.6 allowed by this specification. The rectangular tube was designed with A572-Gr. 50 steel material $\left(F_{y}=320 \mathrm{MPa}\right.$ or $\left.46 \mathrm{ksi}\right)$, while the circular one was designed with A500-Gr.B steel material ( $F_{y}=290 \mathrm{MPa}$ or $42 \mathrm{ksi}$ ) as specified in the AISC-LRFD code (e.g. AISC [13]). The inside core was modeled as the confined concrete with $f_{c}^{\prime}=27.9 \mathrm{MPa}$.

Table 1. P-M Interaction Strength Formulas for Five Specific Points

\begin{tabular}{|c|c|c|}
\hline Point & Equation for RCFT & Equation for CCFT \\
\hline (A) & $\begin{array}{l}P_{A}=A_{s} F_{y}+A_{c}\left(0.85 f_{c}^{\prime}\right) \\
M_{A}=0 \\
A_{s}=\text { area of steel shape } \\
A_{c}=h_{1} h_{2}-0.858 r_{i}^{2}\end{array}$ & $\begin{array}{lrl}P_{A} & =A_{S} F_{y}+0.85 f_{c}^{\prime} A_{c} * & r_{m}=\frac{d-t}{2} \\
M_{A}=0 & A_{c}=\frac{\pi h^{2}}{4} \\
A_{S}=\pi r_{m} t & \end{array}$ \\
\hline (E) & $\begin{array}{l}P_{E}=\frac{1}{2}\left(0.85 f_{C}^{\prime}\right) A_{C}+0.85 f_{c}^{\prime} h_{1} h_{E}+4 F_{y} t_{w} h_{E} \\
M_{E}=M_{\max }-\Delta M_{E} \\
Z_{s E}=b h_{E}^{2}-Z_{c E} \quad Z_{c E}=h_{1} h_{E}^{2} \\
\Delta M_{E}=Z_{s E} F_{y}+1 / 2 Z_{c E}\left(0.85 f_{c}^{\prime}\right) \\
h_{E}=\frac{h_{n}}{2}+\frac{d}{4}\end{array}$ & $\begin{aligned} P_{E}= & \left(0.85 f_{c}^{\prime} A_{C}+F_{y} A_{s}\right)-1 / 2\left[F_{y}\left(d^{2}-h^{2}\right)+1 / 2\left(0.85 f_{c}^{\prime}\right) h^{2}\right]\left[\theta_{2} / 2-\sin \theta_{2} / 2\right. \\
M_{E} & =Z_{S E} F_{y}+1 / 2 Z_{c E}\left(0.85 f_{C}^{\prime}\right) \\
h_{E} & =\frac{h_{n}}{2}+\frac{d}{4} \quad h=d-2 t \\
Z_{S E} & =\frac{d^{3} \sin ^{3}\left(\theta_{2} / 2\right)}{6}-Z_{C E} \quad Z_{c E}=\frac{h^{3} \sin ^{3}\left(\theta_{2} / 2\right)}{6} \\
\theta_{2} & =\pi-2 \arcsin \left(2 h_{E} / h\right)\end{aligned}$ \\
\hline (C) & $\begin{aligned} P_{C} & =A_{c}\left(0.85 f_{c}^{\prime}\right) \\
M_{C} & =M_{B}\end{aligned}$ & $\begin{array}{l}P_{C}=0.85 f_{c}^{\prime} A_{c} \\
M_{C}=M_{B}\end{array}$ \\
\hline (D) & $\begin{aligned} P_{D} & =\frac{0.85 f_{c}^{\prime} A_{c}}{2} \\
M_{D} & =Z_{s} F_{y}+1 / 2 Z_{c}\left(0.85 f_{c}^{\prime}\right) \\
Z_{s} & =\text { full y-axis plastic section modulus of steel shape } \\
Z_{c} & =\frac{h_{1} h_{2}^{2}}{4}-0.192 r_{i}^{3}\end{aligned}$ & $\begin{array}{l}P_{D}=\frac{0.85 f_{c}^{\prime} A_{c}}{2} \\
M_{D}=Z_{s} F_{y}+1 / 2 Z_{c}\left(0.85 f_{c}^{\prime}\right) \quad h=d-2 t \\
Z_{s}=\text { plastic section modulus of steel shape }=\frac{d^{3}}{6}-Z_{c} \\
Z_{c}=\frac{h^{3}}{6}\end{array}$ \\
\hline (B) & $\begin{aligned} P_{B} & =0 \\
M_{B} & =M_{D}-Z_{s n} F_{y}-1 / 2 Z_{c n}\left(0.85 f_{c}^{\prime}\right) \\
Z_{s n} & =2 t_{w} h_{n}^{2} \\
Z_{c n} & =h_{1} h_{n}^{2} \\
h_{n} & =\frac{0.85 f_{c}^{\prime} A_{c}}{2\left[0.85 f_{c}^{\prime} h_{1}+4 t_{w} F_{y}\right]} \leq \frac{h_{2}}{2}\end{aligned}$ & $\begin{array}{l}P_{B}=0 \\
M_{B}=Z_{s B} F_{y}+1 / 2 Z_{c B}\left(0.85 f_{c}^{\prime}\right) \\
Z_{s B}=\frac{d^{3} \sin ^{3}\left(\frac{\theta_{1}}{2}\right)}{6}-Z_{c B} \quad \begin{array}{l}K_{c}=f_{c}^{\prime} h^{2} \\
K_{s}=F_{y} r_{m} t\end{array} \\
Z_{c B}=\frac{h^{3} \sin ^{3}\left(\frac{\theta}{2} / 2\right)}{6} \quad h_{n}=\frac{h}{2} \sin \left(\frac{\pi-\theta}{2}\right) \leq \frac{h}{2} \\
\theta_{1}=\frac{0.0260 K_{c}-2 K_{s}}{0.0848 K_{c}}+\frac{\sqrt{\left(0.0260 K_{C}+2 K_{S}\right)^{2}+0.857 K_{C} K_{S}}}{0.0848 K_{C}}\end{array}$ \\
\hline
\end{tabular}

The numerical CFT beam-column specimens are made up of flexible elements based on nonlinear stress-strain material response with discrete fiber sub-regions (e.g. quadrilateral, circular and triangular shapes). The material properties for CFT columns were simulated utilizing the effects of isotropic strain hardening, Bauschinger behavior, and biaxial stress for the steel tube and the uniaxial compressive Kent-Scott-Park stress-strain behavior model for confined concrete. The latter includes the effects of stress degradation and crack opening and closing (e.g. Mazzoni et al. [9]). 
Table 2. Simplified Equations Determined for ESRs

\begin{tabular}{|c|c|}
\hline Prior condition & Simplified equation \\
\hline$P_{r}<P_{D}$ & $\frac{M_{r}}{M_{B}}<1$ \\
\hline$P_{r} \geq P_{D}$ & $\frac{P_{r}-P_{D}}{P_{A}-P_{D}}+\frac{M_{r}}{M_{D^{\prime}}} \leq 1$ \\
\hline
\end{tabular}

The numerical test setup for a fiber based nonlinear beam-column element is shown in Figure 3 (a). Both element deformations and forces were recorded at each integration point. These integration points can be converted into simple zero-length section elements to extract the force-deformation relationship (i.e. $P-\varepsilon$ or $M-\phi$ ) for the composite cross section (e.g. Mazzoni et al. [9]; Varma et al. [10]). This section element is defined by the two nodes at the same position and discrete fiber based section as shown in Figure 3 (b). The test section model was subjected to various levels for the axial force, roughly corresponding to the axial load levels of five interpolation points given by the code provisions. Therefore, the fiber section analyses were conducted on the section elements based on the loading control that the constant axial load level as applied first and then the moment was continuously increased.

Table 3. Summarize Table for C-MF Structures

\begin{tabular}{|c|c|c|c|c|}
\hline C-MF Type & $\begin{array}{l}\text { Yield Shape and Main } \\
\text { Deformation }\end{array}$ & SDC & Moment Connections & Other System Requirements \\
\hline C-PRMF & $\begin{array}{l}\text { Limited yielding occurs in } \\
\text { column base and main yielding } \\
\text { occurs in the ductile components. }\end{array}$ & $\begin{array}{c}\mathrm{C} \\
\text { or } \\
\text { below }\end{array}$ & $\begin{array}{l}\text { A nominal strength is at least equal to } 50 \\
\text { percent of } \mathrm{M}_{\mathrm{p}} \text {. Connections shall be } \\
\text { capable of sustaining the total inter-story } \\
\text { drift of } 0.04 \mathrm{rad} \text {. }\end{array}$ & $\begin{array}{l}\text { Composite beams shall be encased } \\
\text { and fully composite. The stiffness of } \\
\text { beams shall be determined by } E I_{e f f} \\
\text { for the composite section. }\end{array}$ \\
\hline C-SMF & $\begin{array}{l}\text { Limited inelastic deformations } \\
\text { occur in the columns and/or } \\
\text { connections and main yielding } \\
\text { occurs in the beams. }\end{array}$ & $\begin{array}{c}\mathrm{D} \\
\text { and } \\
\text { above }\end{array}$ & $\begin{array}{l}\text { The required strength shall be determined } \\
\text { with the expected flexural strength }\left(R_{y} \mathrm{M}_{\mathrm{n}}\right) \text {. } \\
\text { Connections shall be capable of sustaining } \\
\text { the total inter-story drift of } 0.04 \mathrm{rad} \text {. }\end{array}$ & $\begin{array}{l}\text { Composite columns shall meet the } \\
\text { requirement of the special seismic } \\
\text { systems of Sec. } 6.4 \text { or Sec. } 6.5 \text { (e.g. } \\
\text { ANSI. } 360-05 \text { [7]), as appropriate. }\end{array}$ \\
\hline C-IMF & $\begin{array}{l}\text { Moderate inelastic deformations } \\
\text { occurs in the columns and/or } \\
\text { connections and main yielding } \\
\text { occurs in the beams }\end{array}$ & $\begin{array}{c}\mathrm{C} \\
\text { and } \\
\text { below }\end{array}$ & $\begin{array}{l}\text { The required strength of connections shall } \\
\text { be based on the plastic capacity of steel } \\
\text { beams. Connections can sustain the total } \\
\text { inter-story drift of } 0.03 \mathrm{rad} \text {. }\end{array}$ & $\begin{array}{l}\text { Composite columns shall meet the } \\
\text { requirement of the intermediate } \\
\text { seismic systems of Sec. } 6.4 \text { or Sec. } \\
6.5 \text {, as appropriate. }\end{array}$ \\
\hline C-OMF & $\begin{array}{l}\text { The limited inelastic action will } \\
\text { occur in the beam, columns } \\
\text { and/or connections }\end{array}$ & $\begin{array}{c}\mathrm{A} \\
\text { and } \mathrm{B}\end{array}$ & $\begin{array}{l}\text { Connections can sustain the total inter- } \\
\text { story drift of } 0.02 \mathrm{rad} \text {. }\end{array}$ & $\begin{array}{l}\text { Composite columns shall meet the } \\
\text { requirement of the ordinary seismic } \\
\text { systems of Sec. } 6.4 \text { or Sec. } 6.5 \text {. }\end{array}$ \\
\hline
\end{tabular}

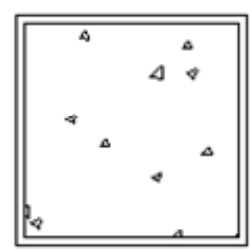

RCFT:HSS16X16X625

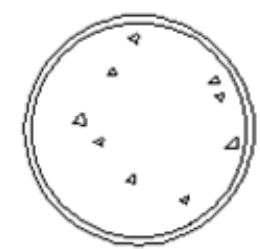

CCFT:HSS18X500
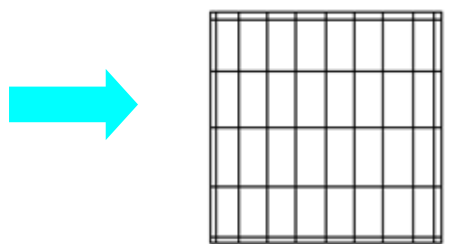

Fiber based beam column elements

Figure 2. Cross Sections for CFT Columns and Idealized Fiber Section Models for Numerical Experiments 
The analytical test results plotted as the moment and curvature response for composite CFT sections are shown in Figure 4 for the case where the zero-length section elements are subjected to the eccentric load. It is composed of a constant axial load corresponding to the axial resistance from half of the pure concrete part (i.e. $P_{D}$ at the Point D shown in Figure 1) and consecutively increasing bending moment. The plastic moment curvature can be captured on the point determined by the computation by dividing the yield stain of the steel tube into the half width of inside concrete, such that $\phi_{P}=2 \varepsilon_{y} / h_{1}$. The plastic moment based on the full plastic yield stress of the steel tube $\left(M_{P}\right)$ is obtained on the plastic moment curvature at the moment and curvature curve (see Figures 4 (a) and (b)). Therefore, the plastic moment capacities of composite CFT sections under each axial force level are able to be estimated through the fiber section analyses (e.g. $M_{P}=M_{D}=1260 \mathrm{kN}-\mathrm{m}$ for HSS16X16X625 section under $P=P_{D}=1644 \mathrm{kN}$; see Figure 4 (a)).

Since the strain hardening effect was assigned into the steel tube sections, the extra section capacity from the plastic yield moment to the ultimate moment $\left(M_{u}\right)$ was provided as shown in the curves. The envelope of the post-yield section behavior can be used to develop the inelastic curvature ductility ratio (ICDR). The proportional slope $\left(K_{i}\right)$ is defined as the initial secant flexural stiffness corresponding to the serviceability level of the moment generally taken as $0.6 M_{u}$ (see Figure (4)). The ICDR is defined as $\phi_{u}$ divided by $\phi_{y} . \phi_{y}$ denotes the curvature at the nominal yield defined as $M_{u}$ divided by $K_{i} . \phi_{u}$ indicates the ultimate curvature. The degree of the post-yield response is well expressed by this ratio. On the other hand, the index defined as the ductility ratio at the structural behavior can change in accordance with the amount of the material strain hardening.
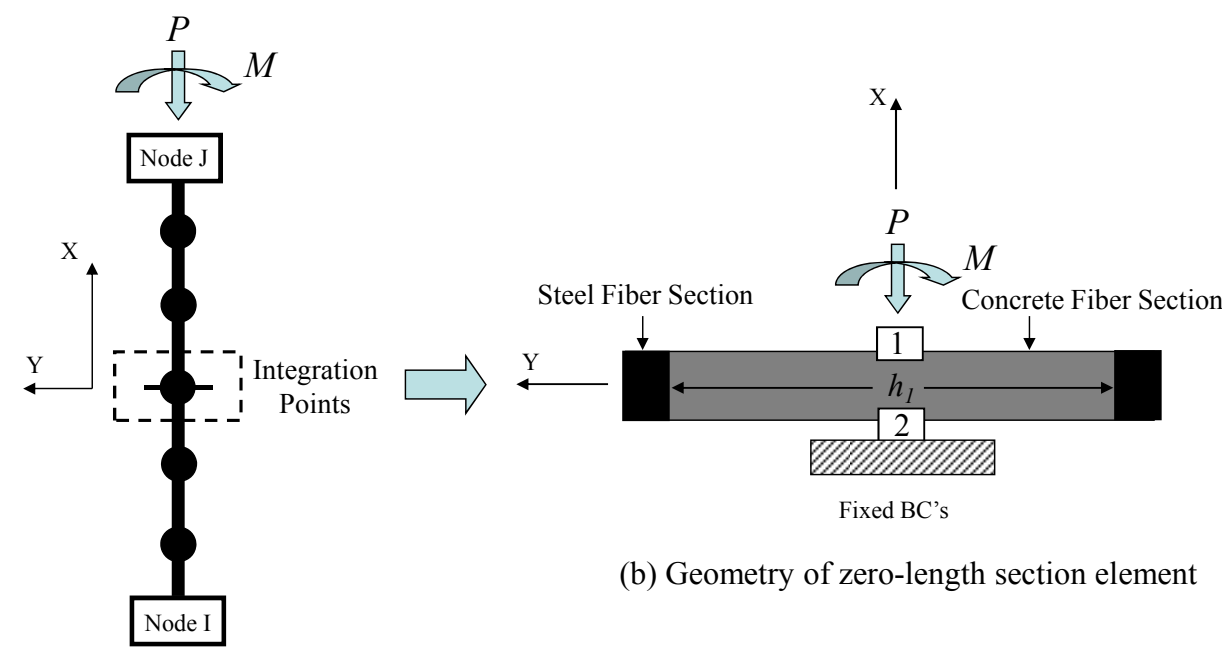

(b) Geometry of zero-length section element

(a) Element for beam-column

Figure 3. Test Setup for the Nonlinear Beam-column Element and Zero-length Section Element

The P-M interaction diagrams resulting from the fiber section analyses are compared with those from the equations listed in Table 1. Comparisons between two diagrams are shown in Figure 5. In addition to the overall plastic yield of steel tube sections, the points obtained by the fiber section analyses are equivalent to the achievement of the maximum concrete strength. P-M interaction diagrams compared to each other show good agreement, indicating that the analytical results are adequate to estimate the capacity of the composite CFT sections with considerable accuracy. 


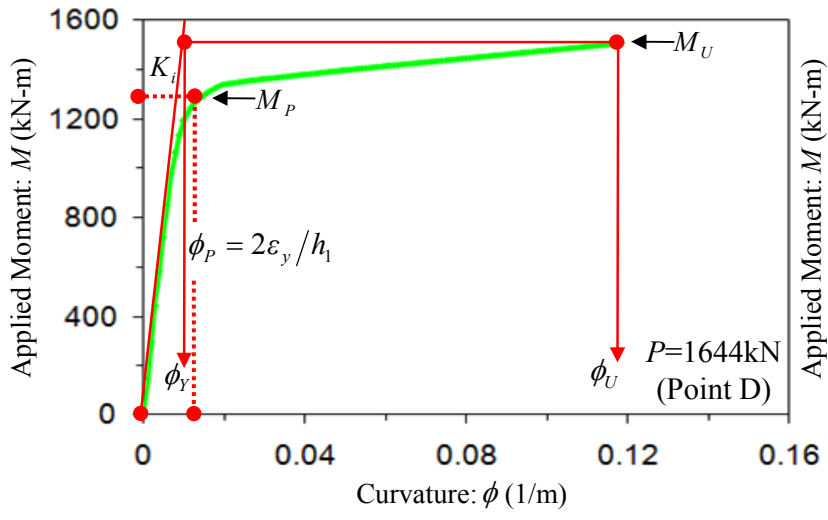

(a) RCFT Column (HSS16X16X625)

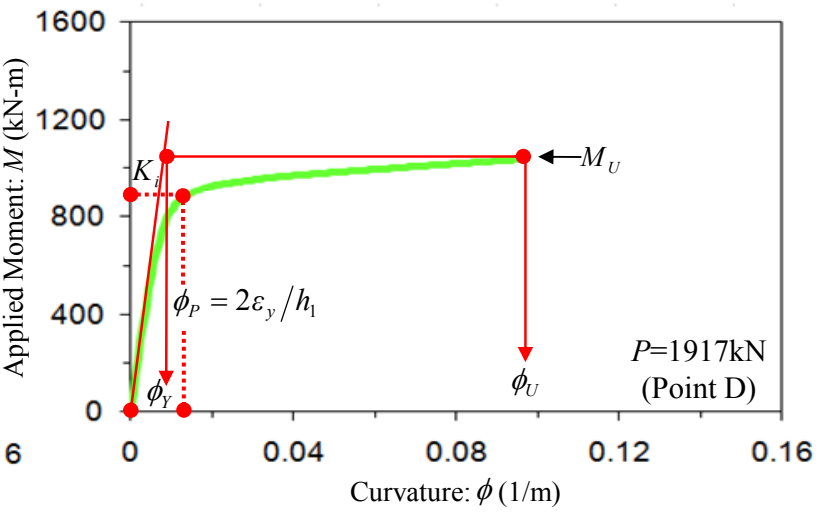

(b) CCFT Column (HSS18X500)

Figure 4. Moment and Curvature response for the composite CFT sections under the axial force $P_{D}$

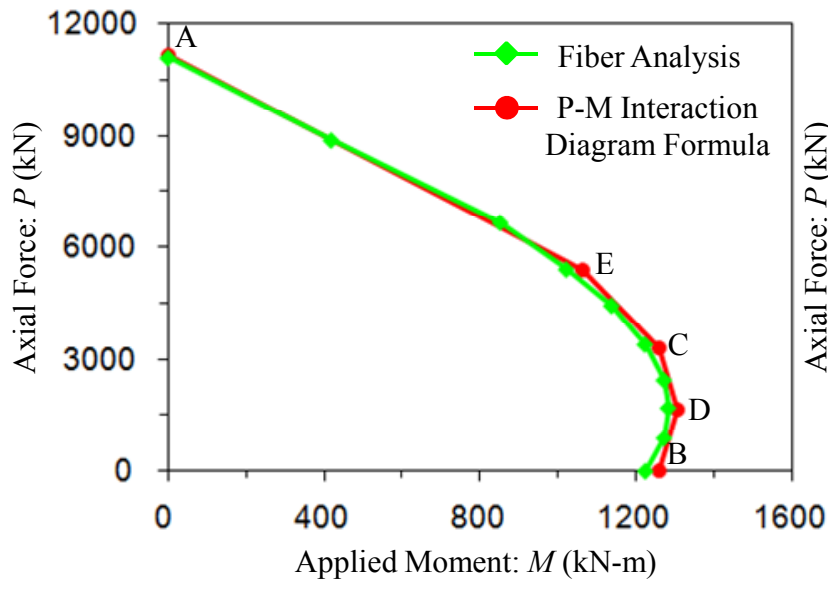

(a) RCFT Column (HSS16X16X625)

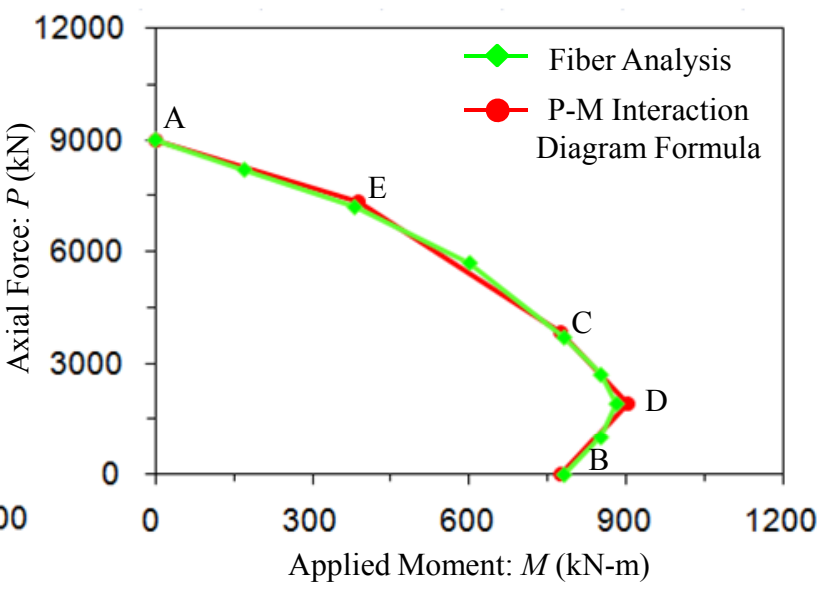

(b) CCFT Column (HSS18X500)

Figure 5. Comparisons of P-M Interaction Diagrams

\section{NONLINEAR FRAME ANALYSES}

For nonlinear frame analyses, five-story composite moment frames were designed with either RCFT columns (5SRCFT model) or CCFT columns (5SCCFT model). These structures were first evaluated using an equivalent static lateral load procedure (pushover) and then using nonlinear dynamic analysis for a ground motion taken from the 1994 Northridge earthquake. Thus, the structures were assumed to be located in LA area with high seismicity corresponding to SDC D and a soil site (e.g. ASCE [12]) and designed by using the mapped spectrum accelerations corresponding to $S_{S}=1.60 \mathrm{~g}$ for the short period and $S_{I}=0.6 \mathrm{~g}$ for 1 second period. The geometric nonlinearity (i.e. P-Delta effect) was included in the frame model. The equivalent lateral loads $\left(E_{a}\right)$ used in the static analysis are based upon the code-calculated period of vibration $(0.79 \mathrm{sec}$.) and not the actual ones $(1.28 \mathrm{sec}$. for the RCFT structure and 1.25 for the CCFT one). The frame models were designed as a composite-special moment frame (C-SMF) for ordinary occupancy and a target story drift limit of 0.02 radians for the 2 percent probability of exceedance in 50 year seismic hazard level. The frame models were detailed in accordance with the Section 10 of the 2005 Seismic Provisions, and overall dimensions and member sizes are shown in Figure 6. The design of this frame was governed by drift considerations, resulting in members with a substantial over-strength factor $(\Omega)$ compared to that required from the strength design case. The frame with RCFT columns was designed with longer bay length along the NS direction than that with CCFT 
columns ( $11 \mathrm{~m}$ for the 5SRCFT model and $9 \mathrm{~m}$ for the 5SCCFT model) because the composite sections used for RCFT columns can accommodate more member capacity as shown in the P-M interaction diagrams (see Figure 5).

For the static pushover analyses, factored dead loads $(D)$ and live loads $(L)$ along with the earthquake loads were applied at the joints using the dominant load combination (i.e. LC5: $1.2 D+1.0 L+1.0 E_{a}$ ) specified in the ASCE07-05. For the dynamic analyses, the unscaled EW base accelerations from the Tarzana station (see Figure 7) recorded during the 1994 Northridge were used. The peak ground acceleration (PGA) for this record is $1.78 \mathrm{~g}$ and this ground motion includes strong directional effects. In the non-linear analyses, a dead load factor of 1.0 and live load factor of 0.2 were used to provide a realistic gravity loading.

The nonlinear frame analyses were performed by the OpenSEES program with all members modeled as nonlinear beam-column elements with discrete fiber sections. The steel beams and composite columns extended from centerline to centerline and met together at a node, and rigid end-offset corresponding to the panel zone was used in the beam elements. All analyses utilized the Newton-Raphson iteration algorithm to ensure equilibrium at each time step. Static pushover analyses were conducted using load a control method, while dynamic analyses were performed by implicit integration using the Newmark-Beta constant acceleration method. For the dynamic analyses, the structural damping ratio was assumed to be 0.025 and the equivalent point masses were applied at the joints as specified in FEMA 355C (e.g. FEMA [14]).

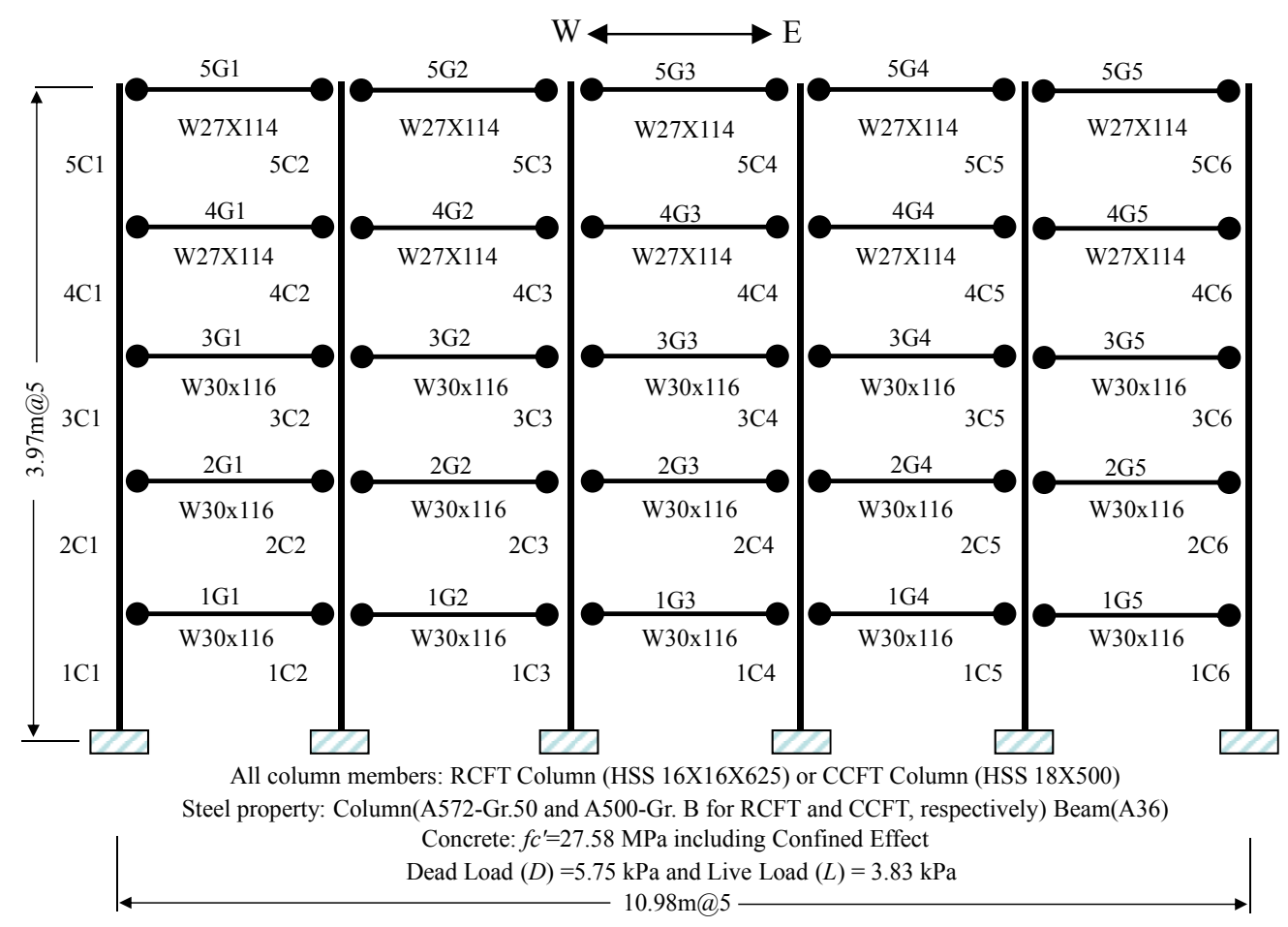

Figure 6. Front View of the 5 Story Composite Moment Frame Model 


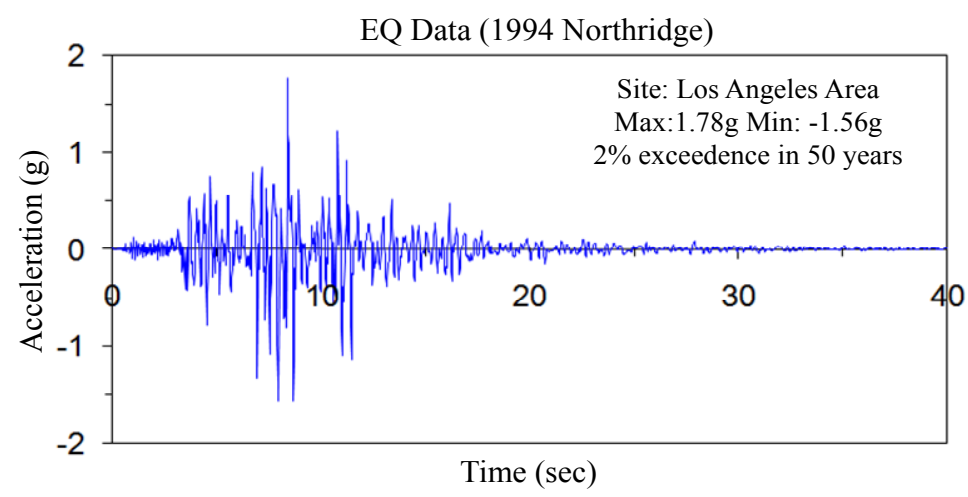

Figure 7. Ground Motion Used for the Nonlinear Dynamic Analysis

The resulting static pushover curves plotted in terms of the story drift ratio (SDR) at the roof level vs. the base shear force normalized by the seismic design base shear force $\left(V / V_{\text {design }}\right)$ are shown in Figure 8. The seismic design base shear force is defined as the summation of the equivalent lateral loads $\left(V_{\text {design }}=\Sigma E_{a}\right)$. The design base shear forces for the 5SRCFT and 5SCCFT model are $1570 \mathrm{kN}$ and $1310 \mathrm{kN}$, respectively. The over-strength ratio was defined as the ratio of the ultimate base shear force to the seismic design base shear force $\left(\Omega=V_{u} / V_{\text {design }}\right)$. This over-strength ratio can be easily observed through the static pushover analyses with displacement control increment and is very useful to examine the strength of the moment frame for the seismic evaluation. The over-strength ratios at both frame models are in close proximity to the value of 3.0 which the guideline recommends during the seismic design (e.g. ASCE [12]). The design point level $\left(\mathrm{V} / V_{\text {design }}=1.0\right)$ is located on the proportionally elastic range.

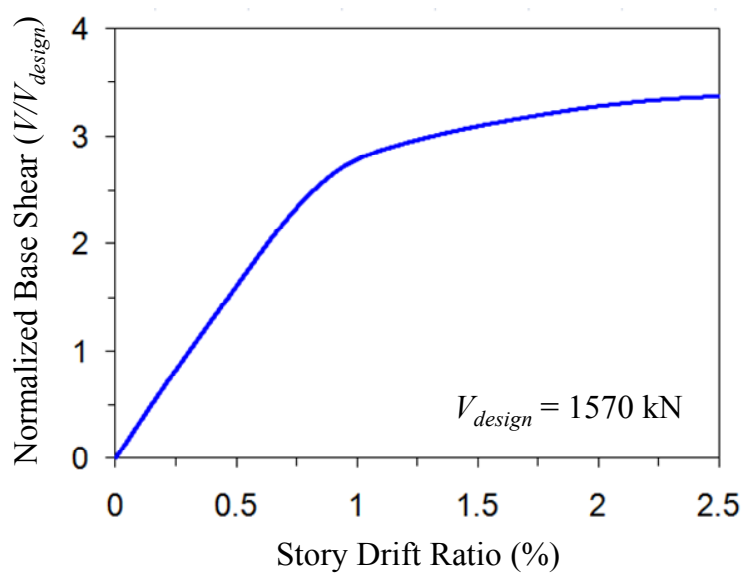

(a) 5SRCFT

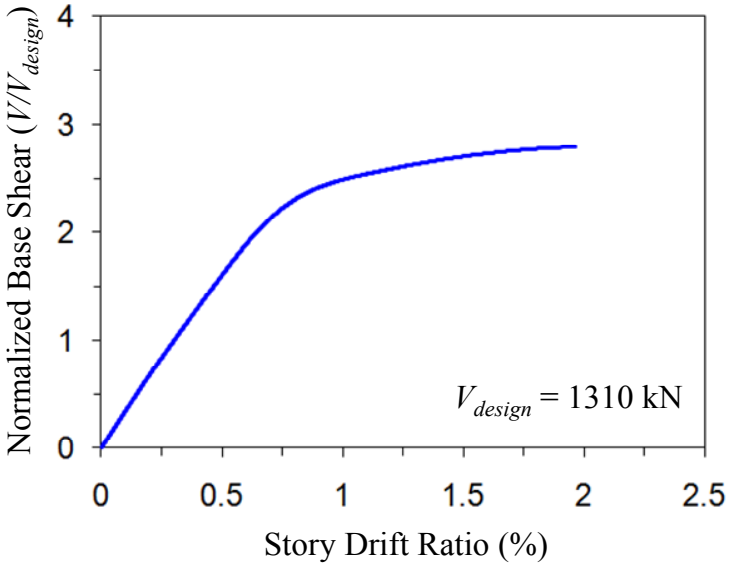

(b) $5 \mathrm{SCCFT}$

Figure 8. Resulting Static Pushover Curves

The results of nonlinear dynamic analyses are shown in Figure 9. The resulting curves are also plotted as the story drift ratio (SDR) at the roof level vs. the base shear force normalized by the seismic design base shear force. Under the ground motion (see Figure 7), the peak roof displacement for the 5SRCFT and 5SCCFT model are roughly $218 \mathrm{~mm}$ and $208 \mathrm{~mm}$, respectively, corresponding to the roof SDR of 1.10 and 1.05 percents. The outbreak time for each peak value slightly lagged behind the time of the PGA (approximately 0.2 second time lag). Overall, the nonlinear dynamic analyses generate slightly larger base shear forces (around 3\%) in comparison with the static pushover analyses at the 1\% SDR level. Based on these nonlinear frame analysis results, the performance based damage evaluation for composite-moment frames is introduced in the next section. 


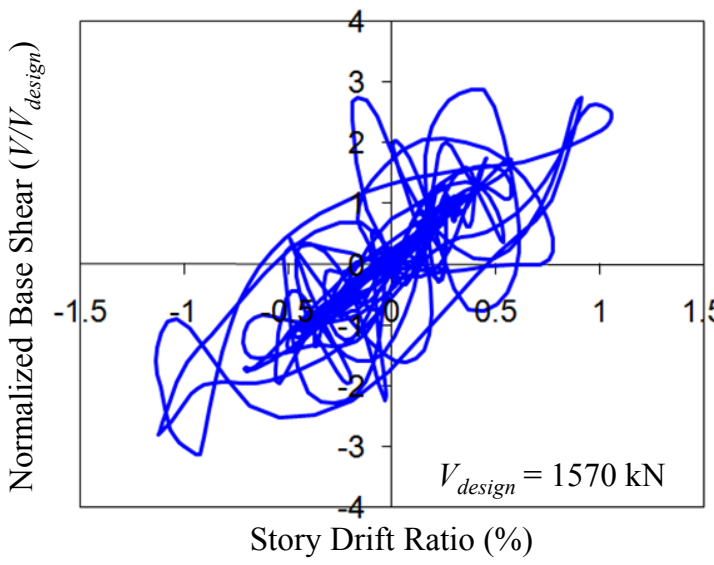

(a) $5 \mathrm{SRCFT}$

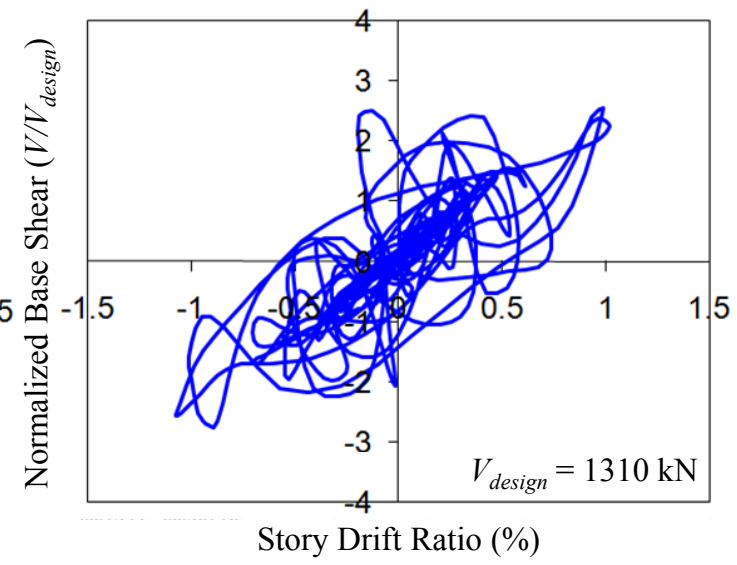

(b) $5 \mathrm{SCCFT}$

Figure 9. Results of Nonlinear Dynamic Analyses

\section{DAMAGE EVALUATION}

The excess of the ultimate limit state in the columns indicates the severe failure state of the building so it leads to the complete collapse. Moreover, there were no available design programs which provide the performance based design check for composite CFT sections. In lieu of the structural beams, the investigation of the structural damage for the composite columns under the seismic loads is emphasized in this study because of these reasons.

There are two steps in proceeding with the damage evaluation, first step associated with determining the capacity and second one with estimating the demand. The member capacity was computed by the P-M interaction diagram for the composite sections based on a full plastic yield stress distribution. To accomplish the second step, the demand at the composite columns must be established from nonlinear frame analyses, which were carried out on a series of entire composite moment frame structures.

The structural damage was estimated in this study through the comparisons of the elastic strength ratios (ESR), which were defined as the ratios of the demand to the strength capacity for the member cross section. Thus, the value of the ESR can be determined by the position of the required strength on the domain of a simplified P-M interaction diagram. Two regions can be identified insofar as axial strength is concerned (see Figure 1). If the required axial strength is low (R2), the behavior of CFT columns is controlled by yielding in tension due to the bending moments. The behavior in this region will be very ductile. It the required axial load is high (R1), the behavior of CFT columns will be dominated by compression due to the axial loads. This will result in only limited ductile behavior. The ESR is defined with the combination of the required axial load $\left(P_{r}\right)$ and bending moment $\left(M_{r}\right)$ as summarized in Table 2. Once P-M interaction forces acting on the CFT columns under seismic loading exceed the conservative limit state referred to as the simplified P-M interaction diagram, the value of the ESR is greater than 1.0. It indicates that the possibility of the plastic yield failure is relatively higher. As mentioned above, the ICDR is another method to estimate the structural damage with respect to the plastic deformation. 
After the nonlinear frame analyses, the performance based damage evaluations referred to as ESRs and ICDRs are summarized in Figs. 10 and 11. The ESRs under the seismic design force level obtained from the static pushover analysis $\left(V / V_{\text {design }}=1.0\right)$ cannot exceed 1.0 even at the bases of CFT columns (e.g. ESR $=0.47$ at the $1 \mathrm{C} 1$ column of 5SRCFT model) because these frame structures satisfied the code requirement for the seismic design. It means that the required member forces of CFT columns subjected to the design earthquake force still exist under the proportional strength limit.

The maximum ESRs and ICDRs resulting from the nonlinear dynamic analysis were computed at the peak member forces under a real ground motion used in this study. The ESRs under the seismic design force level are considerably smaller than those under the peak response from the nonlinear dynamic analysis. Therefore, extensive member failure and overall frame damage can occur due to the actual strong seismic ground motion. A symbol "-" in Figures 10 and 11 indicates that the member force did not exceed the yield point. An ESR of over 0.95 under dynamic loads indicates that the observed member exceeded its yield point and will potentially be subject to a large ductility demand. Overall, the relatively higher ESRs are distributed over the lower story levels because of the larger lumped masses converted from the gravity loads plus the partial live loads. The higher ICDRs also concentrate on the lower story level. Especially, the peak values generally occur at the bases of interior columns $(1 \mathrm{C} 2 \mathrm{~B}, 1 \mathrm{C} 3 \mathrm{~B}, 1 \mathrm{C} 4 \mathrm{~B}$, and $1 \mathrm{C} 5 \mathrm{~B})$. This implies that the composite columns located in the lower story levels are susceptible to severe plastic deformations under this ground motion. Both indies for the damage evaluation decrease as the story level moves up the frame. The values of ESRs less than 1.0 were distributed over more than third story level, and so the possibility of the failure at the upper floor level is relatively lower. All frame models are symmetric in plan and subjected to uniform gravity loads along all bays and stories. Therefore, the values for damage evaluation show a similar distribution along the exterior or interior CFT column lines (e.g. $1 \mathrm{C} 1$ to $5 \mathrm{C} 1$ and $1 \mathrm{C} 6$ to $5 \mathrm{C} 6$ for an exterior column line; $1 \mathrm{C} 3$ to $5 \mathrm{C} 3$ and $1 \mathrm{C} 4$ to $5 \mathrm{C} 4$ for an exterior column line).

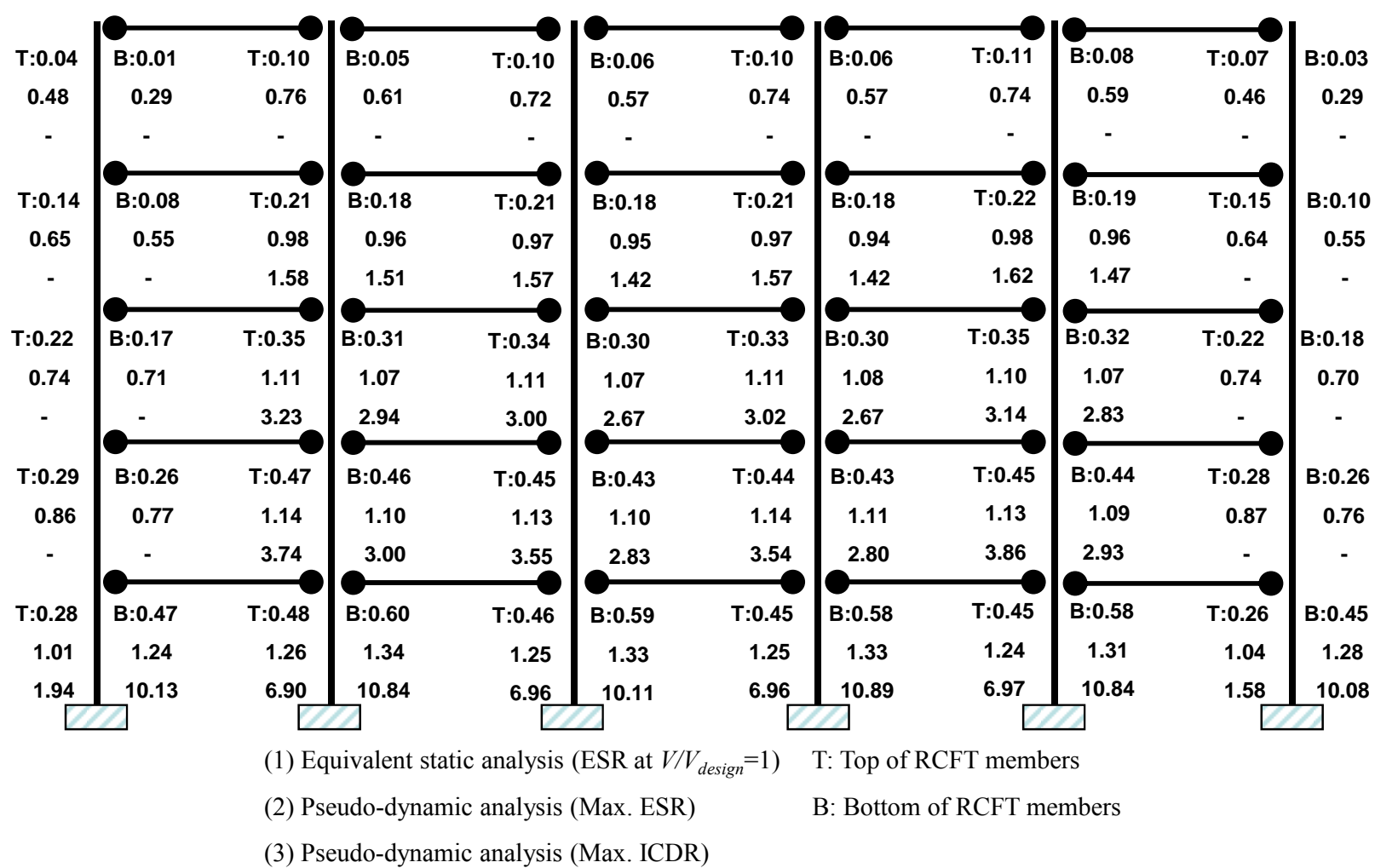

Figure 10. ESRs and ICDRs Distributed Over the 5SRCFT Model 


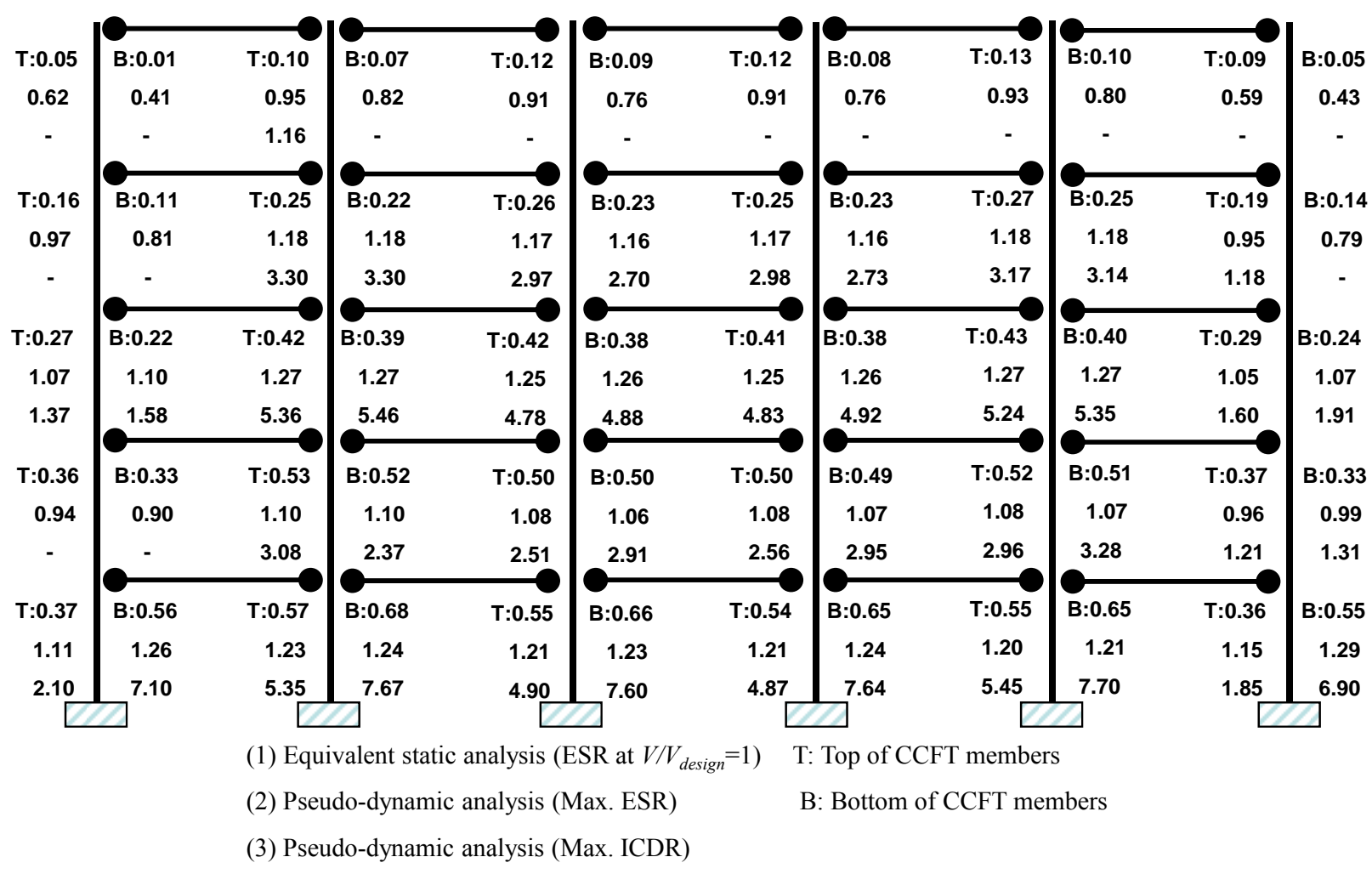

Figure 11. ESRs and ICDRs Distributed over the 5SCCFT Model

\section{CONCLUDING REMARKS}

The new 2005 AISC Specification was used to estimate P-M interaction diagrams for composite CFT beam-columns and the 2005 Seismic Provisions were used for the design of several low-rise composite-moment frame structures. The comparisons between fiber analysis results obtained by numerical experiments and interaction diagrams obtained by AISC design formulas indicate that full plastic capacities by this new design code are quite reasonable for predicting the interaction strength for composite beam-columns.

For the nonlinear frame analyses, both ESRs and ICDRs obtained from nonlinear dynamic analyses show significant correlation with predicted damage based on the excessive deformation. Similar numerical distribution trends between ESRs and ICDRs are observed in both RCFT frame and CCFT frame structures and larger values are found in interior CFT columns of the lower floors when structure models are subjected to either static or dynamic loading. ESR and ICDR values decrease moderately with increasing building story, so damage in the upper floor columns is not expected.

Finally, it is concluded with these reasonable proofs that the evaluation approaches proposed herein are convenient and accurate to check the damage of the entire frame structures subjected to the seismic loads. 


\section{ACKNOWLEDGEMENTS}

The first author would like to also sincerely thank the National Science Foundation (NSF) for six years of financial support (US Grant No. 0324542) as a research assistantship and a post-doctorate fellowship at Georgia Tech.

\section{NOTATIONS}

$A_{c}$ : Cross section area of a concrete core

$A_{s}$ : Cross section area of a steel tube

$E_{s}$ : Elastic modulus of steel

$F_{y}$ : Yield stress of steel (e.g. $F_{y}=350 \mathrm{MPa}$ for A572-Gr.50 carbon steel)

$F_{u}$ : Ultimate stress of steel (e.g. $F_{u}=590 \mathrm{MPa}$ for A572-Gr.50 carbon steel)

$M$ : Applied moment

$M_{A}=\ldots=M_{E}$ : Available flexural strength (Capital subscript indicates the observed point)

$P$ : Applied axial force

$P_{A}=\ldots=P_{F}$ : Available axial strength (Capital subscript indicates the observed point)

$Z_{S B}=Z_{S E}$ : Plastic section modulus of steel shape at Points (B) and (E)

$Z_{c B}=Z_{c E}$ : Plastic section modulus of concrete shape at Points (B) and (E)

$b:$ Width of the composite section

$d$ : Depth or diameter of the composite section

$d_{b}$ : Depth of the steel beam

$d_{c}$ : Depth of the composite column

$f_{c}^{\prime}$ : Crushing strength of concrete

$h$ : Height of the concrete core (e.g. $h_{2}=d-2 t_{f}$ )

$h_{n}=h_{E}$ : Equivalent height of the composite section between center and PNA

$r_{m}$ : Effective radius of the CFT section

$t$ : Thickness of the steel tube

$t_{w}$ : Thickness of the web of the steel tube

$t_{f}$ : Thickness of the flange of the steel tube

$\varepsilon_{c}^{\prime}$ : Uni-axial compressive strain of concrete corresponding to $f_{c}^{\prime}$

$\varepsilon_{y}:$ Yield strain of the steel tube

$\phi$ : Moment curvature of the composite section

$\phi_{p}$ : Plastic moment curvature of the composite section

$\phi_{u}$ : Ultimate moment curvature of the composite section

$\theta$ : Arc angle 


\section{REFERENCES}

[1] Roeder, C.W., "Seismic Behavior of Steel Braced Frame Connections to Composite Columns", Connections in Steel Structure 4, AISC, 2000, pp. 51-62.

[2] Azizinamini, A. and Schneider, S P., "Moment Connections to Circular Concrete-filled Steel Tube Columns", Journal of Structural Engineering, ASCE, 2004, Vol. 130, No. 2, pp. 213-222.

[3] Hajjar, J.F., "Composite Steel and Concrete Structural Systems for Seismic Engineering" Journal of Constructional Steel Research, 2002, Vol. 58, pp. 703-723.

[4] Hu, J.W., Kang, Y.S., Choi, D.H. and Park, T., "Seismic Design, Performance, and Behavior of Composite-moment Frames with Steel Beam-to-concrete Filled Tube Column Connections", International Journal of Steel Structures, KSSC, 2010, Vol. 10, No. 2, pp. 177-191.

[5] Rassati, G.A., Leon, R.T. and Noe, S., "Component Modeling of Partially Restrained Composite Joints under Cyclic and Dynamic Loading”, Journal of Structural Engineering, ASCE, 2004, Vol. 130, No. 2, pp. 343-351.

[6] Green, T.P., Leon, R.T. and Rassati, G.A., "Bidirectional Tests on Partially Restrained, Composite Beam-column Connections", Journal of Structural Engineering, ASCE, 2004, Vol. 130, No. 2, pp. 320-327.

[7] 2005 AISC Specification, "Specification for Structural Steel Buildings (ANSI/AISC 360-05)", 2005, Chicago, IL.

[8] 2005 AISC Seismic Provision, "Seismic Provisions for Structural Steel Buildings (ANSI/AISC 341-05)", 2005, Chicago, IL.

[9] Mazzoni, S., Mckenna, F. and Fenves, G.L., "OpenSEES Command Language Manual”, Department of Civil Environmental Engineering, 2005, University of California, Berkley, CA.

[10] Varma, A.H. et al., "Seismic Behavior and Design of High-strength Square Concrete-filled Steel Tube Beam Columns" Journal of Structural Engineering, ASCE, 2004, Vol. 130, No. 2, pp. 169-179.

[11] Galambos, T.V., "Guide to Stability Design Criteria for Steel Structures, Structural Stability Research Council", $5^{\text {th }}$ Edition, John Wiley and Sons, 1998, New York, NY.

[12] American Society of Civil Engineers (ASCE), "Minimum Design Loads for Buildings and Other Structures" ASCE 7-05, 2005.

[13] American Institute of Steel Contraction (AISC), "Manual of Steel Construction, Load, and Resistance Factor Design (LRFD)", $3^{\text {rd }}$ Edition, 2001, Chicago, IL.

[14] Federal Emergency Management Agency (FEMA), "State of the Art Report on Systems Performance of Steel Moment Frames Subjected to Earthquake Ground Shaking", Rep. No. FEMA-355C, 2000, Washington, DC. 